\title{
Correlates of food patterns in young Latino children at high risk of obesity
}

\author{
Lucia L Kaiser ${ }^{1, *}$, Alberto L Aguilera ${ }^{1}$, Marcel Horowitz ${ }^{2}$, Catherine Lamp ${ }^{3}$, \\ Margaret Johns ${ }^{4}$, Rosa Gomez-Camacho ${ }^{5}$, Lenna Ontai ${ }^{6}$ and Adela de la Torre ${ }^{5}$ \\ 'Department of Nutrition, University of California at Davis, 3207 Meyer Hall, One Shields Avenue, Davis, CA \\ 95616-5270, USA: ${ }^{2}$ University of California Cooperative Extension, Woodland, CA, USA: ${ }^{3}$ University of California \\ Cooperative Extension, Tulare, CA, USA: ${ }^{4}$ University of California Cooperative Extension, Bakersfield, CA, USA: \\ ${ }^{5}$ Center for Transnational Health, University of California at Davis, Davis, CA, USA: ${ }^{6}$ Department of Human Ecology, \\ University of California at Davis, Davis, CA, USA
}

Submitted 6 June 2014: Final revision received 20 0ctober 2014: Accepted 9 December 2014: First published online 29 January 2015

\begin{abstract}
Objective: The present paper examines the influence of age and gender on food patterns of Latino children.

Design: Data are from baseline of a 5-year, quasi-experimental obesity prevention study: Niños Sanos, Familia Sana (NSFS; Healthy Children, Healthy Families). In 2012, the researchers interviewed Latino parents, using a thirty-item questionnaire to ask about their children's food consumption and feeding practices. Statistical tests included $t$ tests and ANCOVA.

Setting: Rural communities in California's Central Valley, USA.

Subjects: Two hundred and seventeen parents (87-89\% born in Mexico) and their children (aged 2-8 years).

Results: Fifty-one per cent of the children were overweight or obese $(\geq 85$ th percentile of BMI for age and gender). Mean BMI $Z$-scores were not significantly different in boys (1.10 (sD 1.07)) and girls (0.92 (sD 1.04); $P=0 \cdot 12)$. In bivariate analysis, children aged 2-4 years consumed fast and convenience foods less often $(P=0.04)$ and WIC (Supplemental Nutrition Program for Women, Infants, and Children)-allowable foods more often than children aged $5-8$ years $(P=0 \cdot 01)$. In ANCOVA, neither age nor gender was significantly related to food patterns. Mother's acculturation level was positively related to children's consumption of fast and convenience foods $(P=0.0002)$ and negatively related to consumption of WIC foods $(P=0 \cdot 01)$. Providing role modelling and structure in scheduling meals and snacks had a positive effect on the vegetable pattern $(P=0.0007)$, whereas meal skipping was associated with more frequent fast and convenience food consumption $(P=0 \cdot 04)$.

Conclusions: Acculturation and child feeding practices jointly influence food patterns in Latino immigrant children and indicate a need for interventions that maintain diet quality as children transition to school.
\end{abstract}



According to the FAO, obesity (BMI $\geq 30 \mathrm{~kg} / \mathrm{m}^{2}$ ) occurs in $32.8 \%$ of Mexican adults, an estimate exceeding that reported for many developed countries including the USA $(31 \cdot 8 \%)^{(1)}$. When Mexican-Americans are compared with their counterparts in Mexico, a greater prevalence of obesity and overweight is observed in the $\mathrm{USA}^{(2-4)}$. As reported by a Mexican national study conducted in 2012, the prevalence of overweight and obesity among Mexican 5 -11-year-olds averages $34.4 \%$, with $36.9 \%$ of boys and $32.0 \%$ of girls at or above the 85 th percentile of $\mathrm{BMI}^{(5)}$. Comparable US national studies from 2009-2010 report an overweight and obesity prevalence of $39.0 \%$ among Mexican-American children aged 6-11 years, with 38.5\% of boys and $39.5 \%$ of girls at or above the 85 th BMI percentile $^{(6)}$. A gender gap for Mexican-American children is apparent by adolescence (12-19 years), when $46 \%$ of Mexican-American boys have $\mathrm{BMI} \geq 85$ th percentile compared with $40 \%$ of girls. This finding is largely due to more boys $(28.9 \%)$ than girls (18.6\%) having BMI $\geq 95$ th percentile for their age and gender. A smaller gender difference is seen among Mexican adolescents, with $14.5 \%$ of boys and $12.1 \%$ of the girls being obese. 
Among the multiple social, economic and environmental factors that contribute to obesity, parenting styles and feeding practices influence the dietary intake and growth of young children ${ }^{(7-13)}$. Recent efforts towards understanding parent contributions to child obesity have differentiated between general parenting styles and parenting practices, each of which makes significant yet distinct contributions to the development of children's dietary behaviours. In contrast to parenting practices focused on directly influencing what a child eats (e.g. restriction of food, serving fruits and vegetables, pressure to eat), general parenting refers to the 'style' that parents adopt in their interactions with their children ${ }^{(14)}$. Parents can fall into one of four general parenting 'styles' based on two dimensions: demandingness (i.e. attempts to control children's behaviour: high or low control) and responsiveness (i.e. acceptance of children's demands and needs: child-centred or parent-centred) ${ }^{(15)}$. Based on ratings of parents' behaviours with their children on these two dimensions, general parenting is classified as 'authoritative', 'authoritarian', 'permissive' or 'neglectful'. This typology has since been applied to feeding styles reflecting demandingness (degree to which parents try to get their children to eat) and responsiveness (degree to which child-centred strategies are used to get children to eat) and result in authoritative, authoritarian, indulgent and uninvolved feeding styles ${ }^{(10)}$. The evidence to date reveals unique associations between child obesity and both authoritative parenting styles, which balance demandingness with child-centred responsiveness, and indulgent feeding practices, which lack proper control over children's dietary environments ${ }^{(16,17)}$.

Less is known about the modifying effects of gender and age on the relationship of parenting styles and practices to the development of obesity in Latino children. For example, in cultures where male children are particularly valued, a permissive parenting style, which is highly responsive but lacks structure and limits, could result in allowing boys to eat too many high-sugar or high-fat snacks $^{(9)}$. A Mexican-based study provides some supporting evidence, concluding that children are more likely to be obese if they are boys, from households with no other or few children and have parents with a permissive parenting style ${ }^{(18)}$. An observational study of 177 families in Texas found that Latino boys (but not girls) of parents with a permissive style are more likely to have increased BMI $Z$-scores, compared with African-American boys ${ }^{(19)}$. In contrast, an overly controlling parenting style, characterized by strict rules, commands and other directive strategies, can also be counterproductive and results in children demanding more of the 'restricted' foods ${ }^{(9)}$. A US study of 812 Latino parents with children in kindergarten through second grade reported that a controlling parenting style is positively related to consumption of unhealthy foods but only in girls ${ }^{(20)}$. Although a study based on the 2003 National Survey of Children's Health found that family meals reduced the risk of obesity in white children of both genders, Latino boys, but not girls, are marginally at greater risk for overweight when family meals are frequent ${ }^{(21)}$.

For Mexican immigrants, acculturation to the USA has been associated with many dietary and lifestyle changes ${ }^{(22-26)}$. Acculturation is a long-term, fluid process in which people adopt aspects of a new culture while simultaneously modifying values, beliefs and/or behaviours associated with their culture of origin ${ }^{(26,27)}$. Although researchers often use structured, validated instruments such as the Cuellar Scale ${ }^{(27)}$ to measure level of acculturation, others may use a proxy such as birthplace or years in the USA to measure this construct. Use of different measures of acculturation and failure to control for effect modifiers have led to contradictory findings in the literature regarding the effect of acculturation on diet and lifestyle.

Nevertheless, several studies report that higher levels of acculturation are negatively related to fruit and vegetable intakes and positively related to intakes of sugarsweetened beverages ${ }^{(24,26)}$ and fast and convenience food items ${ }^{(28)}$. One study suggests that boys and girls may respond differently to acculturation. A study among fourth graders (1646 boys and 1861 girls) in Texas public schools found that greater acculturation is associated with less frequent milk and fruit consumption in Latino boys, but not in girls ${ }^{(29)}$.

For US-born children of immigrant parents, the transition to school provides greater contact with mainstream culture and is a time when several factors coalesce to influence food patterns. At 60 months of age, children are no longer eligible for food assistance from the federal Special Supplemental Nutrition Program for Women, Infants, and Children (WIC). However, upon entry to school, immigrant children can participate in the school nutrition programmes (School Breakfast, Lunch and Supper) and thus are exposed to menus and foods that may differ from those offered in the homes of newly arrived, immigrant families. Research on the effect of this transition to school on the diet of immigrant children is sparse. Cross-sectional US data document that fruit and vegetable intakes are lower in 6-11-year-olds, compared with 2-5-year-olds ${ }^{(30)}$. Although this trend is also observed in Mexican-American children, it is not clear how food patterns change among immigrant children as they grow older. In a longitudinal study, a larger proportion of acculturated youth in the school student body has been associated with more rapid linguistic acculturation of entering students but no data were available on diet, physical activity or other lifestyle changes ${ }^{(31)}$.

Niños Sanos, Familia Sana (NSFS; Healthy Children, Healthy Family) is a 5-year, community-based intervention to prevent obesity in young Latino children through nutrition education and an economic incentive to purchase fruit and vegetables ${ }^{(32)}$. In 2012, baseline data were collected in the intervention and comparison communities in Fresno County, located in California's Central Valley. 
The purpose of the present paper is to examine the influence of maternal and household-level factors and child's age and gender on food patterns of children aged 2-8 years, using baseline data from the NSFS study. Specific research questions include the following: (i) Do gender (male) and older age influence child food patterns to reflect a less healthy diet (more fast and convenience foods and fewer vegetables)? (ii) Is there a modifying role of gender and age on the relationship of child feeding practices to food patterns?

\section{Methods}

\section{Participants}

Participants included 303 children enrolled in the baseline sample of the NSFS intervention ${ }^{(32)}$. Over $90 \%$ of the population in these communities is of Latino descent, primarily from Mexico. Inclusion criteria for the present analysis were: (i) at least one child between 2 and 8 years of age; (ii) residence within targeted school districts; and (iii) mother and/or father self-identified as being of Mexican, Hispanic, Latino or Chicano ethnicity. The study was approved by the Institutional Review Board of the University of California at Davis. Parents or legal guardians signed informed consent forms in their preferred language (Spanish or English).

\section{Measures}

The study used an FFQ to capture child food patterns. This instrument consisted of twenty-six items related to consumption of specific foods or beverages in the past month and used a Likert response scale ( $1=$ 'never/rarely'; $2=$ ' 1 time or less a week'; 3='2-3 times a week'; $4=$ ' 1 time a day'; and $5=$ 'more than once a day'). The twenty-six food items were selected based on studies in Mexican-origin households ${ }^{(28,33)}$. In a binational study ${ }^{(28)}$, a US food pattern, based on FFQ items including hamburgers, pizza, hot dogs, fried chicken, cheese, pastries, juice and instant cereal, demonstrated good construct validity and internal reliability (Cronbach's $\alpha=0.77$ ) and was positively correlated with BMI $Z$-score $(r=0.24$, $P<0.0003)$ in young Mexican-origin children. In a Mexicanorigin population in California, the fruit and vegetable FFQ items yielded estimates of pre-school children's fruit and vegetable intakes that were significantly correlated with household food supplies ${ }^{(33)}$. Four items related to child feeding practices and adapted from previous research were included in the questionnaire ${ }^{(34)}$. These items asked about whether the child eats with an adult, consumes meals and snacks on a regular schedule, and skips meals. Responses included: $1=$ 'no/rarely'; $2=$ 'sometimes'; $3=$ 'often'; and $4=$ 'very often'. The pictures and wording of the final instrument were cognitively tested with seven Spanish-speaking community health workers. Their feedback on interpretation of the words and pictures informed modifications to ensure cultural relevance and comprehension of the final instrument. Researchers used the Brief Acculturation Rating Scale for Mexican-Americans, with a twelve-item Likert scale to measure acculturation using two subscales: the Mexican Orientation Subscale and the Anglo Orientation Subscale ${ }^{(27)}$. Back-translation of the instruments was performed to ensure the items were identical.

\section{Data collection}

Bilingual researchers, certified by the Institutional Review Board of the University of California at Davis, administered the FFQ to the parent or caregiver who responded for his/her children enrolled in the NSFS study. Because the goal was to examine changes in diet over the course of the intervention (including transition to school), interviewers selected one 1-5-year-old pre-school child per household for the FFQ administration. Where the household had multiple children or children outside that age range, parents responded to the FFQ items for the youngest child.

The research team measured height and weight of the children. Weight was recorded to the nearest $0.2 \mathrm{~kg}$ on a portable balance, and height to the nearest $0.1 \mathrm{~cm}$ using a stadiometer as described elsewhere ${ }^{(32)}$. The team measured each child twice, and the average was used to calculate BMI. The BMI Z-score for each child used the Centers for Disease Control and Prevention growth references ${ }^{(35)}$.

\section{Analysis}

The researchers analysed data using the SAS statistical software package version 9.3. Descriptive statistics (medians, means or frequencies) were calculated for the demographic variables. Two separate factor analyses with varimax rotation assisted in identifying underlying patterns related to (i) food intake and (ii) child feeding practices (daily structure of meals/snacks and role modelling). The strongest factors included those with eigenvalues greater than 1.0. Absolute factor loading $>0.40$ was used as the cut-off for determining which items belonged to a particular pattern. Based on the factor analysis, the researchers created food pattern and child feeding scales by summing several highly correlated individual items into a score. For this step, the full Likert range of responses was used. To maximize internal consistency or reliability, items above the 0.40 cut-off were retained in the scale if their inclusion increased the Cronbach's $\alpha$ coefficient (desirable $\alpha$ coefficient $\geq 0 \cdot 7)^{(36)}$. In bivariate analyses, Student's $t$ test determined the effect of age and gender on weight status as measured by BMI $Z$-score and food pattern scales. The researchers used ANCOVA to examine the effects of age group (2-4 years or 5-8 years) and gender on food patterns. Covariates included maternal acculturation, age, marital status and education; number of siblings; and household participation in food assistance programmes including WIC and the Supplemental Nutrition Assistance 
Program (SNAP). Interactions of age and gender with child feeding practices were examined. Statistical significance was set at $P=0 \cdot 05$, with $P=0 \cdot 10$ considered as marginally significant.

\section{Results}

Table 1 shows demographic characteristics of the families in the study. Of the 303 families interviewed, complete food consumption and child feeding practices data were available for 217 children. The reason for missing data was due to respondents not answering one or more items in the FFQ. There were no significant differences in child's BMI Z-score, household income, participation in food assistance programmes, maternal age or marital status among families with complete or missing data (data not shown). However, compared with those with complete data, mothers with missing data had lived more years in the USA (17.4 v. 12.8 years, $P=0.0004)$ and were more educated (11.0 v. 9.3 years of schooling, $P=0.002)$. Eighty-nine per cent $(n$ 163) of fathers and $87 \%$ ( $n$ 188) of mothers were born in Mexico. Eight per cent of fathers ( $n$ 16) and $11 \%$ of mothers ( $n$ 23) were US-born. The remainder of fathers $(2 \%, n 4)$ and mothers $(2 \%, n 5)$ were born in Central America. Among mothers, $73.6 \%$ ( $n$ 159) were categorized having a low (traditional) acculturation level; $16 \cdot 2 \%$ ( $n$ 35) as low bicultural; $7 \cdot 4 \%$ ( $n$ 16) as high bicultural; and $3 \%(n$ 6) as assimilated. There were no significant differences in BMI $Z$-score by age group or gender (Table 1). Prevalence of overweight and obesity (BMI for age and gender $\geq 85$ th percentile) was $51 \%$ ( $n$ 100) for the total sample.

\section{Food patterns}

Factor analysis in Table 2 reveals three clear food patterns. A 'fast/convenience pattern' included pizza, hamburgers, hot dogs, canned fruit, instant noodles, spaghetti sauce, fried potatoes, chips and soft drinks. A second food pattern ('vegetable pattern') included vegetables in different forms, including vegetable soup; other cooked vegetables (except potatoes); lettuce or cabbage; other raw forms of produce; and Mexican-style salsa. A third food pattern ('WIC pattern') included many items allowable for purchase with WIC vouchers, such as low-fat milk, fresh fruit, readyto-eat cereal, juice and corn tortillas. Internal consistency or reliability of the scale based on the fast/convenience and vegetable food patterns was good (Cronbach's $\alpha=0.74$ and 0.70 , respectively), but reliability of the WIC food pattern scale was lower $(\alpha=0 \cdot 58)$.

\section{Effects of age and gender on food patterns and child feeding practices}

Table 3 shows the relationships of age and gender with food patterns, based on bivariate analyses. Gender was not related to any of the three food patterns. Compared with children aged $2-4$ years, older children (aged $5-8$ years) consumed fast and convenience foods more often $(P=0.04)$ and tended to consume WIC food items less often $(P=0 \cdot 10)$. No effect of age was observed on the frequency of consuming vegetables.

\section{Multivariate analyses}

When maternal and household characteristics and child feeding practices (role modelling, scheduling of dinner and snacks, meal skipping) were included in the models, the effect of child's age on the frequency of fast and

Table 1 Demographic characteristics of the study families ( $n$ 217); Niños Sanos, Familia Sana (NSFS; Healthy Children, Healthy Families), California's Central Valley, USA, 2012

\begin{tabular}{|c|c|c|c|c|}
\hline Variable & Mean & SD & $\%$ & $n$ \\
\hline Child's age (months) & $59 \cdot 2$ & $15 \cdot 2$ & & \\
\hline Child's gender (male) & & & $52 \cdot 1$ & 113 \\
\hline Maternal age (years) & 33.7 & $6 \cdot 6$ & & \\
\hline Maternal education (years) & $9 \cdot 3$ & 3.6 & & \\
\hline Paternal education (years), $n 180$ & 8.2 & 3.9 & & \\
\hline Mother lives with spouse or partner (yes) & & & $81 \cdot 1$ & 176 \\
\hline Household size (number) & 4.9 & 1.3 & & \\
\hline Income (\$US/month), n 211 & 1847 & 1093 & & \\
\hline Income $\leq 185 \%$ of federal poverty level, $n 210$ & & & $95 \cdot 3$ & 201 \\
\hline Enrolled in WIC* (yes) & & & $78 \cdot 3$ & 170 \\
\hline Income $\leq 130 \%$ of federal poverty level, $n 210$ & & & 88.2 & 184 \\
\hline Enrolled in SNAP* (yes) & & & $57 \cdot 6$ & 125 \\
\hline Years in USA, foreign-born mothers, $n 180$ & $12 \cdot 7$ & $6 \cdot 9$ & & \\
\hline Years in USA, foreign-born fathers, $n 156$ & $17 \cdot 9$ & $8 \cdot 1$ & & \\
\hline \multicolumn{5}{|l|}{ BMI† Z-score, $n 197$} \\
\hline All children & 1.01 & 1.06 & & \\
\hline Boys, $n 102$ & $1 \cdot 10$ & 1.07 & & \\
\hline Girls, $n 95$ & 0.92 & 1.04 & & \\
\hline $2-4$ years, $n 103$ & 1.07 & $1 \cdot 10$ & & \\
\hline $5-8$ years, $n 94$ & 0.95 & 1.02 & & \\
\hline
\end{tabular}

WIC, Special Supplemental Nutrition Program for Women, Infants and Children; SNAP, Supplemental Nutrition Assistance Program. *Family has one or more members enrolled in the federal WIC or SNAP programme.

†BMI $Z$-score ( $t$ test): boys $v$. girls, NS; 2-4 years $v$. 5-8 years, NS. 
Table 2 Food patterns based on factor analysis ( $n$ 217); Niños Sanos, Familia Sana (NSFS; Healthy Children, Healthy Families), California's Central Valley, USA, 2012

\begin{tabular}{|c|c|c|c|}
\hline \multirow[b]{2}{*}{ Food item } & \multicolumn{3}{|c|}{ Factor loading (orthogonal rotation) } \\
\hline & Fast/convenience pattern & Vegetable pattern & WIC pattern \\
\hline Fried beans & +0.12306 & +0.24076 & +0.22551 \\
\hline Corn tortillas & -0.02785 & +0.31193 & +0.49569 \\
\hline Rice & +0.34265 & +0.20583 & +0.04098 \\
\hline Pizza & +0.60471 & +0.00152 & -0.08388 \\
\hline Hamburgers & +0.59410 & $+0 \cdot 11245$ & -0.12818 \\
\hline Hot dogs & +0.58573 & +0.02311 & -0.15693 \\
\hline Fried chicken & +0.33785 & -0.05304 & +0.08392 \\
\hline Soft drinks & +0.51624 & +0.12012 & +0.11909 \\
\hline Low-fat milk & -0.19139 & +0.01953 & +0.57778 \\
\hline Fruit drinks* & +0.36525 & $-0 \cdot 18148$ & +0.41710 \\
\hline Juice† & +0.03756 & +0.07481 & +0.62893 \\
\hline Ready-to-eat cereal & +0.08982 & 0.07246 & +0.63499 \\
\hline Instant noodles & +0.58859 & -0.07093 & -0.03655 \\
\hline American cheese & +0.36565 & $0 \cdot 19119$ & +0.03655 \\
\hline Quesadillas & +0.37970 & +0.29422 & +0.20959 \\
\hline Fresh fruit & $-0 \cdot 16620$ & +0.39967 & +0.42488 \\
\hline Canned fruit & +0.44362 & +0.07719 & +0.05219 \\
\hline Vegetable soup & +0.08524 & +0.58392 & +0.10449 \\
\hline Fried potatoes & +0.60681 & -0.09655 & +0.07490 \\
\hline Other cooked vegetables (not potatoes) & -0.03063 & +0.66496 & +0.06653 \\
\hline Lettuce or cabbage & +0.05553 & $+0 \cdot 73107$ & +0.00238 \\
\hline Other raw vegetables $\ddagger$ & -0.00044 & +0.71346 & +0.05835 \\
\hline Salsa & +0.07764 & +0.53920 & -0.12416 \\
\hline Spaghetti sauce & +0.53219 & +0.08024 & -0.09909 \\
\hline Cookies or crackers & +0.23583 & -0.02262 & +0.14573 \\
\hline Snack foods§ & +0.49921 & -0.01755 & -0.01061 \\
\hline Eigenvalue & 1.7 & $1 \cdot 1$ & 1.0 \\
\hline
\end{tabular}

${ }^{*}$ Including Tampico ${ }^{\circledR}$, Caprisun $^{\circledR}$ and Sunny Delight ${ }^{\circledR}$.

†Including $100 \%$ fruit juice and agua fresca, a traditional Mexican beverage made with water and fresh fruit. †lncluding cucumber, jicama, radish and carrots.

§including Hot Cheetos ${ }^{\circledR}$ and chips.

Table 3 Child food patterns by age and gender ( $n$ 217); Niños Sanos, Familia Sana (NSFS; Healthy Children, Healthy Families), California's Central Valley, USA, 2012

\begin{tabular}{|c|c|c|c|c|c|c|c|c|c|c|}
\hline \multirow[b]{3}{*}{ Variable } & \multicolumn{5}{|c|}{ Age } & \multicolumn{5}{|c|}{ Gender } \\
\hline & \multicolumn{2}{|c|}{$2-4$ years $(n 122)$} & \multicolumn{2}{|c|}{$5-8$ years $(n 95)$} & \multirow[b]{2}{*}{$\begin{array}{c}P \\
\text { value }\end{array}$} & \multicolumn{2}{|c|}{ Female ( $n$ 104) } & \multicolumn{2}{|c|}{ Male $(n 113)$} & \multirow[b]{2}{*}{$\begin{array}{c}P \\
\text { value }\end{array}$} \\
\hline & $\begin{array}{c}\text { Mean or } \\
\text { median }\end{array}$ & $\begin{array}{l}\text { SD or } \\
\text { IQR }\end{array}$ & $\begin{array}{l}\text { Mean or } \\
\text { median }\end{array}$ & $\begin{array}{l}\text { SD or } \\
\text { IQR }\end{array}$ & & $\begin{array}{l}\text { Mean or } \\
\text { median }\end{array}$ & $\begin{array}{l}\text { SD or } \\
\text { IQR }\end{array}$ & $\begin{array}{l}\text { Mean or } \\
\text { median }\end{array}$ & $\begin{array}{l}\text { SD or } \\
\text { IQR }\end{array}$ & \\
\hline Fast/convenience foods score ${ }^{*}$ & & & & & 0.04 & & & & & NS \\
\hline Median and IQR & 16 & 5 & 17 & 5 & & 16 & 4 & 16 & 6 & \\
\hline Mean and SD & $15 \cdot 8$ & 3.9 & $17 \cdot 0$ & 4.3 & & $16 \cdot 2$ & $4 \cdot 1$ & $16 \cdot 4$ & $4 \cdot 1$ & \\
\hline Vegetable score $†$ & & & & & NS & & & & & NS \\
\hline Median and IQR & 13 & 5 & 13 & 4 & & 13 & 4 & 13 & 5 & \\
\hline Mean and SD & $13 \cdot 1$ & $3 \cdot 8$ & $12 \cdot 8$ & $3 \cdot 1$ & & 13.0 & $3 \cdot 3$ & $13 \cdot 0$ & 3.7 & \\
\hline WIC foods score $\ddagger$ & & & & & 0.10 & & & & & NS \\
\hline Median and IQR & 20 & 5 & 19 & 4 & & 20 & 5 & 19 & 4 & \\
\hline Mean and SD & 19.5 & 3.0 & $18 \cdot 7$ & 3.0 & & $19 \cdot 3$ & 3.4 & $19 \cdot 0$ & 3.1 & \\
\hline
\end{tabular}

IQR, interquartile range; WIC, Supplemental Nutrition Program for Women, Infants, and Children.

${ }^{*}$ Fast/convenience foods score is a sum of responses (range: 9-36) for frequency of consuming pizza, canned fruit, hamburgers, soft drinks, hot dogs, instant noodles, fried potatoes, snack foods and spaghetti sauce. Cronbach's $a=0.74$ ( $t$ test).

†Vegetable score is a sum of responses (range: 5-20) for frequency of consuming vegetable soup, other cooked vegetables (not potatoes), lettuce/cabbage, other raw vegetables and salsa. Cronbach's $a=0.70$ ( $t$ test).

$\ddagger W I C$ foods score is a sum of responses (range: 5-20) for frequency of consuming low-fat milk, juice, ready-to-eat cereal, corn tortillas and fruit. Cronbach's $a=0.58$ ( $t$ test).

convenience foods was only marginally significant $(P=0 \cdot 10$; Table 4). However, maternal acculturation $(P=0.0002)$ and child skips meals $(P=0.04)$ were positively associated with the fast/convenience food pattern. SNAP participation was marginally related to the fast/convenience food pattern $(P=0 \cdot 08)$. No main effects or interactions (data not shown) of age group and gender with child feeding practices or any of the other variables were observed. 
Table 4 ANCOVA: children's food patterns ( $n$ 217); Niños Sanos, Familia Sana (NSFS; Healthy Children, Healthy Families), California's Central Valley, USA, 2012

\begin{tabular}{|c|c|c|c|c|c|c|c|c|c|}
\hline \multirow[b]{2}{*}{ Variable } & \multicolumn{3}{|c|}{ Fast/convenience* } & \multicolumn{3}{|c|}{ Vegetable† } & \multicolumn{3}{|c|}{ WIC $\ddagger$} \\
\hline & $\beta$ & SE & $P$ value & $\beta$ & SE & $P$ value & $\beta$ & SE & $P$ value \\
\hline Mother's education (years) & -0.02 & 0.09 & 0.79 & -0.03 & 0.07 & 0.65 & -0.04 & 0.07 & 0.58 \\
\hline Mother's age (years) & +0.07 & 0.04 & 0.12 & +0.06 & 0.04 & 0.13 & -0.01 & 0.04 & 0.81 \\
\hline Mother's acculturation§ & +1.53 & 0.40 & 0.0002 & -0.42 & 0.34 & 0.21 & -0.64 & 0.33 & 0.05 \\
\hline Married/partner $(0=$ no; $1=$ yes $)$ & +0.35 & 0.72 & 0.62 & +1.50 & 0.61 & 0.02 & +0.21 & 0.58 & 0.72 \\
\hline WIC benefits $(0=$ no; $1=$ yes $)$ & $\begin{array}{c}\text { Not } \\
\text { included }\end{array}$ & & & $\begin{array}{c}\text { Not } \\
\text { included }\end{array}$ & & & +1.45 & 0.57 & 0.01 \\
\hline SNAP benefits $(0=$ no; $1=$ yes $)$ & +1.08 & 0.58 & 0.08 & +0.27 & 0.49 & 0.59 & -0.38 & 0.48 & 0.42 \\
\hline Siblings (number) & $+0 \cdot 15$ & 0.25 & 0.56 & +0.59 & 0.21 & 0.006 & $+0 \cdot 28$ & 0.20 & $0 \cdot 18$ \\
\hline Age group $(1=2-4$ years; $2=5-8$ years $)$ & +0.91 & 0.55 & $0 \cdot 10$ & -0.76 & 0.46 & 0.11 & $\begin{array}{c}\text { Not } \\
\text { included }\end{array}$ & & \\
\hline Gender $(1=$ male; $2=$ female $)$ & +0.45 & 0.55 & 0.41 & +0.03 & 0.46 & 0.95 & +0.06 & 0.44 & 0.89 \\
\hline Structurell & -0.07 & 0.16 & 0.64 & +0.45 & 0.13 & 0.0007 & $+0 \cdot 11$ & 0.13 & 0.38 \\
\hline Skips meals $\mathbb{1}$ & +0.96 & 0.46 & 0.04 & +0.58 & 0.38 & 0.14 & -0.41 & 0.36 & 0.26 \\
\hline $\begin{array}{l}\text { Df } \\
\left.R^{2} \text { ( } P \text { value }\right)\end{array}$ & \multicolumn{3}{|c|}{$\begin{array}{c}10 \\
0.14(0.000)\end{array}$} & \multicolumn{3}{|c|}{$\begin{array}{c}10 \\
0.17(0.0001)\end{array}$} & \multicolumn{3}{|c|}{$\begin{array}{c}10 \\
0.09(0.03)\end{array}$} \\
\hline
\end{tabular}

WIC, Special Supplemental Nutrition Program for Women, Infants and Children; SNAP, Supplemental Nutrition Assistance Program.

${ }^{*}$ Fast/convenience foods score is a sum of responses (range: 9-36) for frequency of consuming pizza, hamburgers, soft drinks, hot dogs, instant noodles, fried potatoes, snack foods, canned fruit and spaghetti sauce (Cronbach's $a=0.74$ ).

†Vegetable score is a sum of responses (range: 5-20) for frequency of consuming vegetable soup, other cooked vegetables (not potatoes), lettuce/cabbage, other raw vegetables and salsa (Cronbach's $a=0.70)$.

$\ddagger \mathrm{WIC}$ foods score is a sum of responses (range: $5-20)$ for frequency of consuming low-fat milk, juice, ready-to-eat cereal, corn tortillas and fruit (Cronbach's $a=0.58)$. §Maternal acculturation: $1=$ traditional (low); $2=$ low bicultural; $3=$ high bicultural; $4=$ assimilated

IIA summed score (range 3-12) of the following items: (i) My child sits and eats with an adult; (ii) My child eats dinner around the same time every day; and (iii) My child eats a snack around the same time every day. Response options for each item: $1=$ 'never/rarely'; $2=$ 'sometimes'; $3=$ 'often'; $4=$ 'very often' (Cronbach's $a=0.55$ ). IFull wording is: My child skips meals. Responses: 1 = 'never/rarely'; 2 = 'sometimes'; 3 = 'often'; 4 = 'very often'.

Child feeding practices (role modelling, regular schedules of dinner and snacks) were positively related to vegetable intake $(P=0 \cdot 0007$; Table 4$)$. Acculturation was not related to vegetable intake. Presence of the mother's spouse or partner $(P=0.02)$ and number of the target child's siblings in the home $(P=0.006)$ were also positively related to vegetable intake. No main effects or interactions (data not shown) of age group and gender with any of the other variables were observed.

Since the age group and WIC participation variables were strongly correlated $(r=0 \cdot 49)$, only one of these variables at a time was included in the models to avoid a multicollinearity problem. Thus, in examining correlates of the WIC food pattern, two separate analyses were run using age group or WIC status. As expected, currently receiving WIC benefits was positively related to the WIC food pattern $(P=0.01$; Table 4$)$ but receiving SNAP was not. After controlling for covariates, older age group was not related to the WIC food pattern ( $\beta=-0.74$ (SE 0.45), $P=0 \cdot 11)$. Greater acculturation was negatively related to the WIC food pattern ( $\beta=-0.62$ (sE 0.32 ), $P=0.05$ ) but the effect was diminished without corn tortillas included in the scale $(\beta=-0.43$ (se $0 \cdot 26), P=0 \cdot 10)$. In this sample, WIC mothers also reported fewer years living in the USA than non-WIC mothers (mean 12.4 v. 17.6 years, $P=0.0007$ ).

\section{Discussion}

In this sample of rural, Mexican-heritage children, neither age group nor gender had a significant effect (main or modifying) on consumption of a fast/convenience or vegetable food pattern after controlling for maternal and household characteristics. Providing role modelling and structure in scheduling meals and snacks had a positive effect on the vegetable pattern, whereas meal skipping was associated with more frequent fast and convenience food consumption. As expected, consumption of foods allowable through the WIC programme was higher among the younger children, compared with the older ones, although the effect was only marginal. Mother's acculturation level was positively related to children's consumption of less healthy foods (fast and convenience foods) and negatively related to consumption of WIC foods.

Prevalence of overweight and obesity was higher in this sample (51\%), compared with national US data for Mexican-American children aged 2-5 years (33.3\%) and $6-11$ years $(39 \cdot 0 \%)^{(6)}$. However, other studies in Mexican immigrant populations have reported estimates similar to ours $(44-49 \%)^{(2,37)}$. No differences by gender or age group were observed.

Our finding that older age was unrelated to vegetable intake differs from national data showing that the percentage of children meeting recommendations for fruit and vegetable consumption is significantly lower among 6-11-year-olds, compared with 2-5-year-olds ${ }^{(30)}$. However, our study only included children up to 8 years of age. Future waves of our study that include older children may reveal significant age effects on vegetable and fruit intake.

Other studies in Latino children (5-12 years) and youth (12-19 years) have reported that acculturation is negatively associated with fruit and vegetable intake, although a 
California study did not find a significant relationship in Latino pre-school children $(3-5 \text { years })^{(38-41)}$. The young age of the children (2-8 years) in our study may explain why no effect of acculturation on vegetable intake was observed. Similar to our findings, other research shows that parenting practices, such as positive role modelling, may partially mitigate negative influences of acculturation on access and availability of fruit and vegetables in Latino households with children ${ }^{(39)}$

The strong effect of acculturation on children's consumption of fast-food items, like pizza, hot dogs, chips, hamburgers and soda, parallels previous research. In a study that compared national survey data from the USA and Mexico, US populations (first- and second-generation Mexican-Americans) reported higher consumption of desserts, pizza, French fries and salty snacks, compared with populations in Mexico ${ }^{(25)}$. These patterns were particularly evident among children and youth. In the Viva la Familia study, conducted in Texas among 1030 Mexican-American 4-19-year-olds, more than $21 \%$ of the total energy intake in overweight boys and girls came from pizza, soda, chips, processed meats and burgers ${ }^{(42)}$. In US children and adults, consumption of fried foods prepared away from home has been linked to greater energy and fat intakes and higher $\mathrm{BMI}^{(43)}$.

Among immigrant children, the increased frequency of consuming fast and convenience foods over time most likely reflects acculturation through increased exposure to foods prepared away from home. This phenomenon is consistent with the epidemiological paradox present in Mexican-origin communities where traditional cultural practices are protective and promote resiliency despite low socio-economic status ${ }^{(44)}$. That is, newly arrived Mexican immigrant parents may be more likely to offer healthy, traditional food choices (for example, vegetable soups) to their children before they enter the public school system. Once these children are exposed to peer influences and the broader food choices offered in US schools, food preferences of these children shift to more American-style foods (for example, pizza and hot dogs). In a previous study also conducted among Latinos in California's Central Valley, $71.8 \%$ ( $n$ 112) of immigrant parents reported offering other foods when their children refuse to eat what families serve at mealtimes ${ }^{(45)}$. Where parents are highly responsive to their children's demands (and refusals) and set few limits or provide little structure, these American-style foods may rapidly displace healthier traditional Mexican foods, like vegetable soups and legumes. A recent study found that when immigrants from different ethnic groups are compared, dietary acculturation occurred most rapidly in Hispanics ${ }^{(46)}$. This observation may be due to highly responsive parent feeding practices and/or to the opportunity for the USA and Mexico to jointly influence dietary patterns due to their close proximity. In the rural community where our study was conducted, parents attribute changes in their children's food habits to exposure to American-style foods offered in the schools. Our data show that the practice of skipping meals at home is also associated with greater consumption of these American-style foods.

In Latino families undergoing acculturation, teasing out the ways that parenting practices influence children's dietary intake requires a deeper appreciation of other factors that may be changing within the household. To make a living in a new country, fathers may work long hours, often at multiple jobs, and arrive home for meals after the children have gone to bed. Particularly after children start school, mothers with higher levels of education and English-speaking skills may be able to enter the job market, leaving the youngest children with older siblings or other caregivers such as a teen-aged relative in charge of managing meals and snacks. Even if mothers only work seasonally, as they do in these communities, this situation may lead to an absence of adult role models at mealtimes and 'grazing' or a lack of structure in meals or snacks. Especially where parents have experienced food deprivation as children, they may feel the need to compensate by stocking the pantry with inexpensive sweet or salty snack foods and allowing their children to choose when, where and what they want to eat ${ }^{(47)}$. Thus, acculturation and economic conditions may all contribute to a household environment that, along with lack of structure and role modelling, has a negative influence on child dietary patterns and ultimately on childhood obesity ${ }^{(17)}$.

Although gender had no apparent effect on the frequency of consumption specific foods, actual amounts consumed were not measured and may differ by gender. Our FFQ was designed only to describe food patterns and does not yield quantitative data on energy and nutrient intakes. A study conducted among Mexican-American families with pre-school children in California found that boys consumed more energy from fat and saturated fat and spent more time watching television or playing video games than did girls ${ }^{(48)}$.

Studies conducted in other populations have reported similar findings linking family-level feeding practices and routines to dietary patterns. In an Australian study, the home food environment, including eating at set times, was positively related to children's fruit and vegetable score ${ }^{(49)}$. In a New York City population of second and fifth graders, skipping meals adversely affected diet quality ${ }^{(50)}$. A metaanalysis of seventeen studies found that the frequency of family meals - namely three or more times weekly - was associated with an increased odds of eating a healthy diet and of having a body weight within a healthy range ${ }^{(51)}$. In combination with neighbourhood-level factors, familylevel factors influencing mealtimes contribute to increased risk of childhood obesity ${ }^{(52)}$.

The present study has several limitations. Parental recall of the child's food intake may be subject to bias. However, the fast/convenience food pattern emerging in the study is consistent with observations reported previously in a 
binational study ${ }^{(28)}$. Baseline FFQ data collection occurred from September 2012 through May 2013. Since the parents responded about the child's food intake during the previous month, seasonal variation, including that due to employment cycles, may have affected the children's dietary intakes. We were unable to examine the effect of food insecurity on dietary patterns in this population because the administration of the food security instrument and the FFQ did not always occur within the same season.

The main strength of the study is the community-based sample of an underserved, high-risk population from a rural, economically disadvantaged area. This population is often difficult to reach due to its geographic location and mobility. For this reason, the study provides valuable information about a rural, immigrant population from Mexico.

The study gathered only semi-quantitative data on the children's diets. Future work should collect energy and nutrient intakes from caregivers of the children to allow further analysis of intakes by gender and/or age group. There is a need for long-term studies to investigate the factors such as parent feeding styles, child feeding practices, acculturation and food insecurity, all of which may have a combined effect on dietary patterns of Mexicanheritage children of pre-school age ${ }^{(13)}$.

\section{New contributions to the literature}

Our findings suggest that acculturation and child feeding practices jointly influence food patterns in Latino, particularly Mexican-origin, immigrant children. Since the transition from home to school is a major life event, future interventions should take advantage of US public school food programmes to encourage parents and schools to work together to support the development of healthy food habits at both school and home. This work should involve a mutual commitment, where the schools in immigrant communities promote healthy, cultural foods to reinforce what families eat at home and parents provide structure and model healthy eating habits that include the fruits, vegetables and whole grains appearing in school meals.

\section{Acknowledgements}

Acknowledgements: The authors would like to acknowledge the contributions of Maria Rangel, Judith Martinez, Ivan Garcia, the families in the study, Dorina Espinoza, Kristen Stenger, Jan Peerson, and graduate and undergraduate student research assistants at the University of California at Davis. Financial support: This project was supported by an Agriculture and Food Research Initiative Competitive Grant (number 2011-68001-30167) and Project CA-D*-NTR-2117-H from the US Department of Agriculture, National Institute of Food and Agriculture. The funders had no role in the design, analysis or writing of this article. Conflict of interest: None. Authorship: The authors contributed as follows. Securing funding: A.d.I.T. and L.L.K.; instrument selection: all; training/supervision of data collectors: A.L.A. and R.G.-C.; data handling and analysis: L.L.K., R.G.-C. and A.L.A.; data interpretation: all; writing of first draft: L.L.K. and A.L.A.; preparation of final draft: all. Ethics of human subject participation: This study was conducted according to the guidelines laid down in the Declaration of Helsinki and all procedures involving human subjects/patients were approved by the University of California at Davis Institutional Review Board. Written informed consent was obtained from all subjects/patients.

\section{References}

1. Food and Agriculture Organization of the United Nations (2013) The State of Food and Agriculture 2013. http://www. fao.org/publications/sofa/en/ (accessed November 2013).

2. Vera-Becerra LE, Lopez LM \& Kaiser LL (2013) Child feeding practices and overweight status among Mexican immigrant families. JImmigr Minor Health (Epublication ahead of print version).

3. Rosas LG, Guendelman S, Harley K et al. (2011) Factors associated with overweight and obesity among children of Mexican descent: results of a binational study. J Immigr Minor Health 13, 169-180.

4. Hernandez-Valero MA, Bustamante-Montes LP, Hernandez M et al. (2012) Higher risk for obesity among Mexican-American and Mexican immigrant children and adolescents than among peers in Mexico. J Immigr Minor Health 14, 517-522.

5. Gutierrez JP, Rivera-Dommarco J, Shamah-Levy $\mathrm{T}$ et al. (2012) Encuesta Nacional de Salud y Nutricion 2012. Resultados Nacionales. Cuernavaca, México: Instituto Nacional de Salud Pública; available at http://ensanut.insp. $\mathrm{mx} /$ doctos/FactSheet_ResultadosNacionales14Nov.pdf

6. Ogden CL, Carroll MD, Kit BK et al. (2012) Prevalence of obesity and trends in body mass index among US children and adolescents, 1999-2010. JAMA 307, 483-490.

7. Chaidez V \& Kaiser LL (2011) Validation of an instrument to assess toddler feeding practices of Latino mothers. Appetite 57, 229-236.

8. Chaidez V, McNiven S, Vosti SA et al. (2013) Sweetened food purchases and indulgent feeding are associated with increased toddler anthropometry. J Nutr Educ Behav $\mathbf{4 6}$, 293-298

9. Olvera N, George G \& Kaiser L (2011) My child is not fat, he's just chubby: a Latino(a) parenting perspective. In $A t$ Risk Latino Children's Health, pp. 87-111 [R Perez-Escamilla and H Melgar-Quiñonez, editors]. Houston TX: Arte Publico Press.

10. Hughes SO, Power TG, Orlet Fisher J et al. (2005) Revisiting a neglected construct: parenting styles in a child-feeding context. Appetite 44, 83-92.

11. Rodenburg G, Kremers SP, Oenema A et al. (2014) Associations of parental feeding styles with child snacking behaviour and weight in the context of general parenting. Public Health Nutr 17, 960-969.

12. Tung HJ \& Yeh MC (2014) Parenting style and child-feeding behaviour in predicting children's weight status change in Taiwan. Public Health Nutr 17, 970-978.

13. Timperio A \& Fulkerson JA (2014) Food-related parenting: issues and challenges. Public Health Nutr 17, 957-959.

14. Darling N \& Steinberg L (1993) Parenting style as context: an integrative model. Psychol Bull 113, 487-496.

15. Maccoby EE \& Martin JA (1983) Socialization in the context of the family: parent-child interaction. In Handbook of Child Psychology. vol. 4: Socialization, Personality, and 
Social Development, 4th ed., pp. 1-101 [PH Mussen and EM Hetherington, editors]. New York: Wiley.

16. Vollmer RL \& Mobley AR (2013) Parenting styles, feeding styles, and their influence on child obesogenic behaviors and body weight. A review. Appetite 71, 232-241.

17. Tovar A, Hennessy E, Pirie A et al. (2012) Feeding styles and child weight status among recent immigrant mother-child dyads. Int J Behav Nutr Phys Act 9, 62.

18. Brewis A (2003) Biocultural aspects of obesity in young Mexican school children. Am J Hum Biol 15, 446-460.

19. Hughes SO, Power TG, Papaioannou MA et al. (2011) Emotional climate, feeding practices, and feeding styles: an observational analysis of the dinner meal in Head Start families. Int J Behav Nutr Phys Act 8, 60.

20. Arredondo EM, Elder JP, Ayala GX et al. (2006) Is parenting style related to children's healthy eating and physical activity in Latino families? Health Educ Res 21, 862-871.

21. Rollins BY, Belue RZ \& Francis LA (2008) The beneficial effect of family meals on obesity differs by race, sex, and household education: the national survey of children's health, 2003-2004. J Am Diet Assoc 110, 1335-1339.

22. Ayala GX, Baquero B \& Klinger S (2008) A systematic review of the relationship between acculturation and diet among Latinos in the United States: implications for future research. J Am Diet Assoc 108, 1330-1344.

23. Perez-Escamilla R \& Putnik P (2007) The role of acculturation in nutrition, lifestyle, and incidence of type 2 diabetes among Latinos. J Nutr 137, 860-870.

24. Batis C, Hernandez-Barrera L, Barquera S et al. (2011) Food acculturation drives dietary differences among Mexicans, Mexican Americans, and Non-Hispanic Whites. J Nutr 141, 1898-1906.

25. Matias SL, Stoecklin-Marois MT, Tancredi DJ et al. (2013) Adherence to dietary recommendations is associated with acculturation among Latino farm workers. J Nutr $\mathbf{1 4 3}$, 1451-1458.

26. Kaiser LL (2009) What can binational studies reveal about acculturation, food insecurity, and diet? J Am Diet Assoc 109, 1997-2000.

27. Cuellar I, Arnold B \& Maldonado R (1995) Acculturation rating scale for Mexican Americans - II: a revision of the original ARSMA scale. Hispanic J Behav Sci 17, 275-304.

28. Vera Becerra LE (2012) Childhood obesity in Mexican-origin populations. PhD Thesis, University of California at Davis.

29. Lind C, Mirchandani GG, Castrucci BC et al. (2012) The effects of acculturation on healthy lifestyle characteristics among Hispanic fourth-grade children in Texas public schools, 2004-2005. J Sch Health 82, 166-174.

30. Lorson BA, Melgar-Quiñonez HR \& Taylor CA (2009) Correlates of fruit and vegetable intakes in US children. $J \mathrm{Am}$ Diet Assoc 109, 474-478.

31. Nieri $\mathrm{T}$ (2012) School context and individual acculturation: how school composition affects Latino students' acculturation. Sociol Inq 82, 460-484.

32. de la Torre A, Sadeghi B, Green RD et al. (2013) Niños Sanos, Familia Sana: Mexican immigrant study protocol for a multifaceted CBPR intervention to combat childhood obesity in two rural California towns. BMC Public Health 13, 1033.

33. Kaiser LL, Martin AC, Metz DL et al. (2004) Food insecurity prominent among low-income California Latinos. Calif Agric 58, 18-23.

34. Anderson SE \& Whitaker RC (2010) Household routines and obesity in US preschool-aged children. Pediatrics 125, $420-428$.
35. Kuczmarski RJ, Ogden CL \& Guo SS (2000) CDC Growth Charts for the United States: methods and development. Vital Health Stat 11, issue 246, 1-190.

36. Santos R (1999) Cronbach's alpha: a tool for assessing reliability of scales. J Extension 37, issue 2; available at http://www.joe.org/joe/1999april/tt3.php

37. Crespo NC, Elder JP, Ayala GX et al. (2012) Results of a multi-level intervention to prevent and control childhood obesity among Latino children: the Aventuras Para Niños Study. Ann Behav Med 43, 84-100.

38. Dave JM, Evans AE, Pfeiffer KA et al. (2010) Correlates of availability and accessibility of fruits and vegetables in homes of low-income Hispanic families. Health Educ Res 25, 97-108.

39. Liu JH, Chu YH, Frongillo EA et al. (2012) Generation and acculturation status are associated with dietary intake and body weight in Mexican American adolescents. J Nutr 142, 298-305.

40. Erinosho TO, Berrigan D, Thompson FE et al. (2012) Dietary intakes of preschool-aged children in relation to caregivers' race/ethnicity, acculturation, and demographic characteristics: results from the 2007 California Health Interview Survey. Matern Child Health J 16, 1844-1853.

41. Wilson TA, Adolph AL \& Butte NF (2009) Nutrient adequacy and diet quality in non-overweight and overweight Hispanic children of low socioeconomic status: the Viva la Familia Study. J Am Diet Assoc 109, 1012-1021.

42. Taveras EM, Berkey CS \& Rifas-Shiman SL (2005) Association of consumption of fried foods away from home with body mass index and diet quality in older children and adolescents. Pediatrics 116, e518-e524.

43. Duerksen SC, Elder JP, Arredondo EM et al. (2007) Family restaurant choices are associated with child and adult overweight status in Mexican-American families. $J$ Am Diet Assoc 107, 849-853.

44. de la Torre A \& Estrada A (2001) Mexican Americans and Health: ¡Sana! ¡Sana! Tucson, AZ: University of Arizona Press.

45. Kaiser LL, Melgar-Quiñonez HR, Lamp CL et al. (2001) Acculturation of Mexican-American mothers influences child feeding strategies. J Am Diet Assoc 101, 542-547.

46. Van Hook J, Quiros S \& Frisco M (2014) The Food Similarity Index: a new measure of dietary acculturation based on dietary recall data. J Immig Minor Health (Epublication ahead of print version).

47. Kuyper E, Smith D \& Kaiser L (2009) Does food insecurity influence child feeding practices? J Hunger Environ Nutr $\mathbf{4}$, $1-11$.

48. Elder JP, Broyles SL, Brennan JJ et al. (2005) Acculturation, parent-child acculturation differential, and chronic disease risk factors in a Mexican-American population. $J$ Immigr Health 7, 1-9.

49. Wyse R, Campbell E, Nathan N et al. (2011) Associations between characteristics of the home food environment and fruit and vegetable intake in preschool children: a crosssectional study. BMC Public Health 11, 938.

50. Melnik TA, Rhoades SJ, Wales KR et al. (1998) Food consumption patterns of elementary schoolchildren in New York City. J Am Diet Assoc 98, 159-164.

51. Hammons AJ \& Fiese BH (2011) Is frequency of shared family meals related to the nutritional health of children and adolescents? Pediatrics 127, e1565-e1574.

52. Fiese BH, Hammons A \& Grigsby-Toussaint D (2012) Family mealtimes: a contextual approach to understanding childhood obesity. Econ Hum Biol 10, 365-374. 